\title{
Programa de Formação Técnica em Enfermagem para Agentes de Saúde: quando uma formação profissional se torna mais uma ameaça ao SUS
}

Em janeiro o Ministério da Saúde (MS) publicou a portaria n. 83/2018 (Brasil, 2018), cujo objeto é a formação profissional dos agentes comunitários de saúde (ACSs) e dos agentes de combate a endemias (ACEs) e cria o Programa de Formação Técnica em Enfermagem para Agentes de Saúde, o PROFAGS. Em síntese, incide sobre as atribuições destes trabalhadores e institui financiamento federal às instituições de ensino, incluindo as privadas. O PROFAGS será executado no biênio 2018-2019 e o processo de formulação de tal Programa apoia-se em reunião realizada no âmbito da Comissão Intergestores Tripartite em dezembro de 2017.

A qualificação profissional dos ACSs vem sendo objeto de disputa desde a institucionalização deste trabalho no âmbito do Sistema Único de Saúde (SUS). Estas disputas integram a dinâmica da produção da política de saúde que, sendo produto da luta de classes, não é isenta dos interesses dos trabalhadores, que reivindicam a universalidade do direito à saúde e à educação; e dos interesses empresariais, que historicamente usufruem do fundo público e tratam a saúde e a educação como mercadorias (Nogueira, 2017).

A publicação do referencial curricular do Curso Técnico em ACS (CTACS), em 2004 (Brasil, 2004), pode ser considerada, em dois sentidos, um avanço para a formação profissional desses trabalhadores. Representa a tentativa de aliar formação profissionalizante à elevação de escolaridade e foi formulado em um processo democrático que incluiu instituições de ensino, representações dos trabalhadores ACSs e setores do MS.

Na contramão do processo de elaboração da proposta do CTACS, a proposição do PROFAGS ocorreu entre gestores, sem a participação dos demais atores com expertise e representatividade histórica na atuação e na formulação de políticas de educação profissional em saúde, como as Escolas Técnicas do SUS (ETSUS). A formação técnica em enfermagem para agentes reedita a proposta de fusão de categorias profissionais contida no relatório do $7^{\circ}$ Fórum Nacional de Gestão da Atenção Básica. Essa fusão se traduz no acirramento da precarização do trabalho e dos riscos de redução dos postos de trabalho, agravada pela proposta da nova Política Nacional de Atenção Básica (PNAB), que fortalece práticas biomédicas curativas e a focalização da Estratégia Saúde da Família (ESF).

Outra potencial repercussão do PROFAGS é a iminente descaracterização profissional que a formação em enfermagem produzirá no processo de trabalho dos agentes. 0 trabalho do ACS é constituído por práticas que incluem mobilização social, interlocução entre os saberes biomédicos e os saberes populares, reivindicação por direitos sociais, mapeamento e acompanhamento das condições sociossanitárias dos territórios que são determinantes no processo de saúde e doença, na produção de informações, na construção de redes de apoio social, no planejamento e execução de ações educativas em saúde. Estas práticas vêm sendo atravessadas pela racionalidade gerencialista, processo que se aprofunda com a implantação de sistemas de avaliação do trabalho em saúde subsidiados por critérios 
de desempenho individual, competitividade entre as equipes, remuneração por desempenho e orientação do trabalho baseado em metas quantitativas centradas em procedimentos biomédicos (Nogueira, 2017). Não por acaso, as portarias n. 958 e 959 publicadas em 2016 pelo MS, e revogadas devido à forte mobilização dos ACSs, foram construídas com a mesma argumentação retomada no PROFAGS, qual seja: a substituição de ACSs por técnicos de enfermagem com vistas à ampliação do escopo de práticas na Atenção Básica (AB) e o suposto aumento da sua resolutividade. O PROFAGS acirrará tanto a burocratização do trabalho dos ACSs quanto a secundarização do trabalho de educação popular em saúde e de acompanhamento dos usuários no território. Este processo tende, inclusive, a aumentar o risco epidemiológico da população pelo desvio de finalidade do trabalho dos ACSs e ACEs, o que se produzirá com a sobreposição de atribuições destes trabalhadores, descaracterizando suas atribuições primordiais.

O trabalho dos ACEs, orientado pela perspectiva de integração das áreas de vigilância em saúde (epidemiológica, sanitária, ambiental e saúde do trabalhador), antecipa-se ao adoecimento, visando, sobretudo, promover a saúde, diferentemente das atividades previstas para o técnico de enfermagem, que atua em procedimentos de intervenção nas situações de doenças instaladas. Trata-se de processos de trabalho complementares e indispensáveis à $\mathrm{AB}$ e sua integração não pode ser confundida com fusão, o que prejudicará as práticas de promoção e de vigilância em saúde.

No que tange à formação profissional dos ACEs, o curso técnico em Enfermagem e o curso técnico em Vigilância possuem bases curriculares distintas. A formação em Vigilância, cujas diretrizes foram publicadas em 2011, é uma proposta do MS iniciada no final dos anos 1990 e fundamenta-se em conhecimentos oriundos da integração das vigilâncias. Estas diretrizes fortalecem a $\mathrm{AB}$ na perspectiva de intervenção nos determinantes sociais e têm como parâmetro os princípios do SUS, assumindo a participação social como estratégica. A proposta do PROFAGS desconsidera ainda o processo de trabalho dos ACEs, profissionais que atuam 'na ponta', por exemplo, enfrentando as arboviroses nos territórios.

No referencial curricular dos cursos técnicos em ACSs e em Vigilância em Saúde o estímulo à participação das ETSUS na oferta dos cursos implica concebê-los como um direito, ofertados de forma gratuita e realizados por instituições públicas, para agentes inseridos no SUS. No caso do CTACS, os temas sugeridos como base do currículo enfatizam o trabalho na $\mathrm{AB}$ e a educação em saúde como centrais (Brasil, 2004). Ainda que os conteúdos do Referencial Curricular do Curso Técnico em ACS necessitem de atualização, já que foram elaborados há 14 anos, registra-se que a formação técnica em ACS contempla vários âmbitos de atuação que informam sobre as atribuições desta categoria profissional, como o trabalho em equipe multiprofissional, a 
promoção da saúde e prevenção de doenças em indivíduos e grupos e as ações voltadas para questões ambientais. A formação técnica em Enfermagem possui competências e conteúdos teóricos que priorizam a atuação em instituições que não são, predominantemente, componentes do nível de atenção primário.

Com a publicação do edital do PROFAGS, confirma-se que não há intenção de se priorizarem as instituições públicas de ensino na captação dos recursos do MS, embora na Classificação Funcional Programática, os recursos financeiros para a execução do Programa onerem a rubrica de "Formação de profissionais técnicos de saúde e fortalecimento das escolas técnicas e centros formadores do SUS". Identifica-se assim o movimento de deslocar recursos que deveriam ser destinados a instituições públicas para a rede privada, que tradicionalmente oferta a Formação Técnica em Enfermagem.

Dentre outras graves inadequações do PROFAGS, está a possibilidade de realização dessa formação na modalidade semipresencial e, conforme publicado na portaria, ser preferencialmente noturno. Isto acarreta a responsabilização dos trabalhadores pela precária formação profissional que o Estado historicamente ofertou além de onerar trabalhadores sabidamente sobrecarregados pela tripla jornada de trabalho, como é o caso dos ACSs, categoria profissional majoritariamente composta por mulheres. Ademais, no PROFAGS punese o trabalhador que não conseguir cumprir a frequência mínima no curso, fazendo-o devolver integralmente ao governo o valor em reais, compromisso que será assumido pelo trabalhador no momento em que assinar um termo de matrícula que prevê tal responsabilização.

A portaria n. 83/208 é mais uma medida do governo federal de focalização da $\mathrm{AB}$ e retirada de direitos e foi promulgada após os vetos ao Projeto de Lei da Câmara (PLC) n. 56/17, que se tornou a lei n. 13.595/18. Estes vetos se referiam a demandas caras aos trabalhadores: formação técnica em ACS e ACE no horário de trabalho e a presença obrigatória dos ACSs na estrutura da AB.

É notório que os interesses privatistas e mercantis que hegemonizam o governo federal tensionaram para a elaboração do PROFAGS. No entanto, as ETSUS, representações sindicais organizadas por ACSs, a Associação Brasileira de Enfermagem e outras entidades estão se posicionando contrariamente ao Programa. A efetivação do direito à formação profissional dos trabalhadores ACSs e ACEs é fundamental para a defesa do SUS, pois eles compõem categorias instituídas e existentes exclusivamente no âmbito da política pública. Constitui-se dever do Estado prover o acesso à formação profissionalizante destes trabalhadores, comprometendo-se com uma política de formação que não impulsione a privatização e o desmonte do SUS. Ao contrário, cabe-nos afirmar a necessidade de prover uma formação profissional específica, voltada para a $\mathrm{AB}$, para o SUS e que se dê, prioritariamente, pelas instituições públicas de ensino. 
A não adesão das ETSUS e dos trabalhadores agentes ao Programa deve fortalecer a defesa pela efetivação de uma política de Educação Profissional que consolide o âmbito de atuação e as atribuições destes trabalhadores. Estas forças políticas devem manter sua articulação em defesa do SUS público e universal, com vistas à efetivação de uma política de formação profissional fomentada pela análise crítica das determinações sociais do processo saúde e doença, pelas ações de promoção da saúde, mobilização social, educação popular e vigilância em saúde.

\section{Mariana Lima Nogueira}

Professora e pesquisadora da Escola Politécnica de Saúde Joaquim Venâncio, Fundação Oswaldo Cruz, Rio de Janeiro, RJ, Brasil.

\section{Ieda da Costa Barbosa}

Professora e pesquisadora da Escola Politécnica de Saúde Joaquim Venâncio, Fundação Oswaldo Cruz, Rio de Janeiro, RJ, Brasil.

\section{Referências}

BRASIL. Ministério da Saúde. Ministério da Educação. Referencial curricular para o curso técnico de agente comunitário de saúde: área profissional saúde. Brasília, DF: Ministério da Saúde, 2004. (Série A. Normas e Manuais Técnicos).

BRASIL. Ministério da Saúde. Portaria n. 83, de 10 de janeiro de 2018. Institui o Programa de Formação Técnica para Agentes de Saúde (PROFAGS), para oferta de curso de formação técnica em enfermagem para agentes comunitários de saúde (ACS) e agentes de combate às endemias (ACE) no âmbito do SUS, para o biênio de 2018-2019. Brasília, DF, 2018. Disponível em: <http://bvsms.saude.gov.br/bvs/saudelegis/gm/2018/prt0083_12_01_2018.html>. Acesso em: 13 jan. 2018.

NOGUEIRA, Mariana L. O processo histórico da Confederação Nacional dos agentes comunitários de saúde: trabalho, educação e consciência política coletiva. 2017. 541f. Tese (Doutorado em Políticas Públicas e Formação Humana ) - Programa de Pós-Graduação em Políticas Públicas e Formação Humana, Universidade do Estado do Rio de Janeiro, Rio de Janeiro.

\begin{tabular}{|l|l}
\hline (cc) BY & Bste é um artigo publicado em acesso aberto sob uma licença Creative \\
Commons.
\end{tabular} 